\title{
Desenvolvimento de Interface em MATLAB para Melhoria do Aprendizado de Tópicos do Eletromagnetismo
}

\author{
Duaymy B. R. Góes Giovane M. da Silva Rafael D. Santos Victor de M. Petta \\ Universidade Federal do Pará - Faculdade de Engenharia Elétrica \\ 66075-110, Campus Guamá, Belém, PA \\ E-mail: petee@yahoogroups.ufpa.br \\ Orlando Fonseca Silva \\ Universidade Federal do Pará - Faculdade de Engenharia Elétrica \\ 66075-110, Campus Guamá, Belém, PA \\ E-mail: orfosi@ufpa.br
}

\begin{abstract}
RESUMO
Um dos maiores paradigmas no ensino de tópicos de eletromagnetismo está no fato de ser necessário trabalhar com conceitos físicos de alta complexidade matemática e de complicada observação prática, que são os campos elétricos e magnéticos. Assim, é de grande auxílio o uso de ferramentas de simulação visual para um melhor entendimento destes conceitos. Neste sentido, este trabalho busca implementar, por meio do software MATLAB [3], um conjunto de interfaces gráficas que permitam representar visualmente características matemáticas das grandezas eletromagnéticas. Nas interfaces, objetos do tipo uicontrol são criados por meio da aba GUIDE, que gera um arquivo para definição de seus callbacks. Além disso, elaborou-se um algoritmo para carregar e unir as informações de todos esses objetos em uma interface única, onde cada simulação fica contida em um painel.

No estudo de campos eletrostáticos, é interessante fazer o uso da Lei de Gauss para conhecer seu comportamento para determinadas simetrias de distribuição de carga [2]. Foi desenvolvida uma interface utilizando esta ideia, com campos de textos editáveis que podem ser usados para inserir parâmetros, na qual o usuário pode escolher entre três opções de distribuição de carga, colocar os parâmetros desejados e obter o comportamento do campo elétrico, tanto em questão do módulo ao longo do tempo, quanto espacialmente. Foi utilizada a função quiver 3 do MATLAB, também chamada de gráfico de velocidade, que plota um gráfico em que em cada ponto determinado há uma seta que representa a direção, sentido e magnitude do campo elétrico neste ponto.

No referente ao estudo de campos elétricos e magnéticos variantes no tempo, trabalhouse com três tópicos fundamentais que também demandam auxílio de ferramentas visuais. Primeiramente, desenvolveu-se uma animação, controlada por botões de início e parada, que permitisse visualizar a propagação de ondas eletromagnéticas com plano de polarização elíptico [1], através de uma plotagem sequencial dos valores de campo elétrico. Para isso, adotaram-se como parâmetros de entrada as constantes de atenuação e fase, as dimensões da elipse, o sentido de giro e a frequência de modo a ser possível observar como o comportamento visual da onda reage à manipulação de cada um destes separadamente. A Figura 1 ilustra a captura de um instantâneo da animação. Para a segunda interface, fez-se a simulação de uma onda de polarização linear mudando de um meio para o outro, sendo a incidência normal. A sua base está em um algoritmo que utiliza os valores de permissividade elétrica, permeabilidade magnética e condutividade dos meios, fornecidos pelo usuário, para calcular os valores instantâneos de campo elétrico e os coeficientes de reflexão e transmissão, de acordo com [2]. Para observar o padrão de onda formado pela reflexão, fez-se uso da opção hold do MATLAB, como é mostrado na Figura 2. Depois de trabalhados este dois tópicos, criou-se uma versão computacional da Carta de Smith onde: o usuário informa as impedâncias para a carga e para a linha e são destacados os círculos de resistência e reatância; em seguida, informam-se os comprimentos de onda e da linha e é feito o correspondente deslocamento de fase, mostrado em animação, no coeficiente de reflexão até o um novo ponto, para o qual são levantados novos
\end{abstract}


círculos. Todos os valores pertinentes ao processo são mostrados na interface, apresentada na Figura 3.

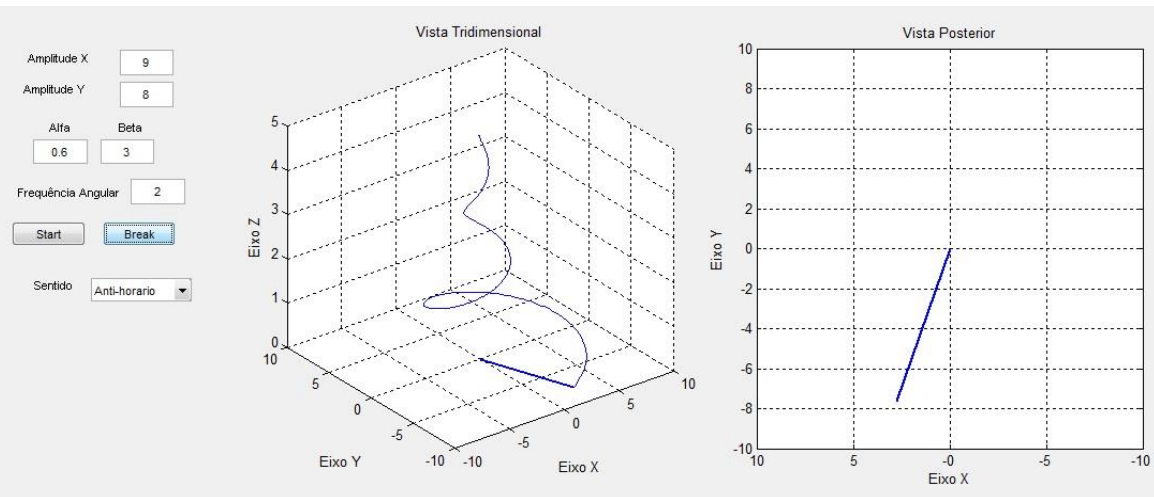

Figura 1: Instantâneo da animação de uma onda se propagando no eixo z

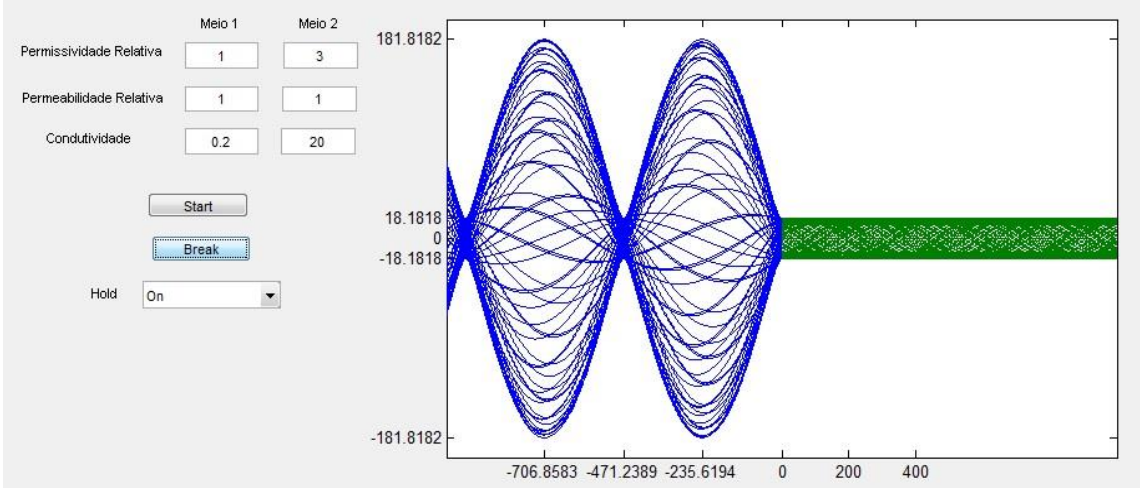

Figura 2: Instantâneo do padrão de onda estacionária gerado por reflexão
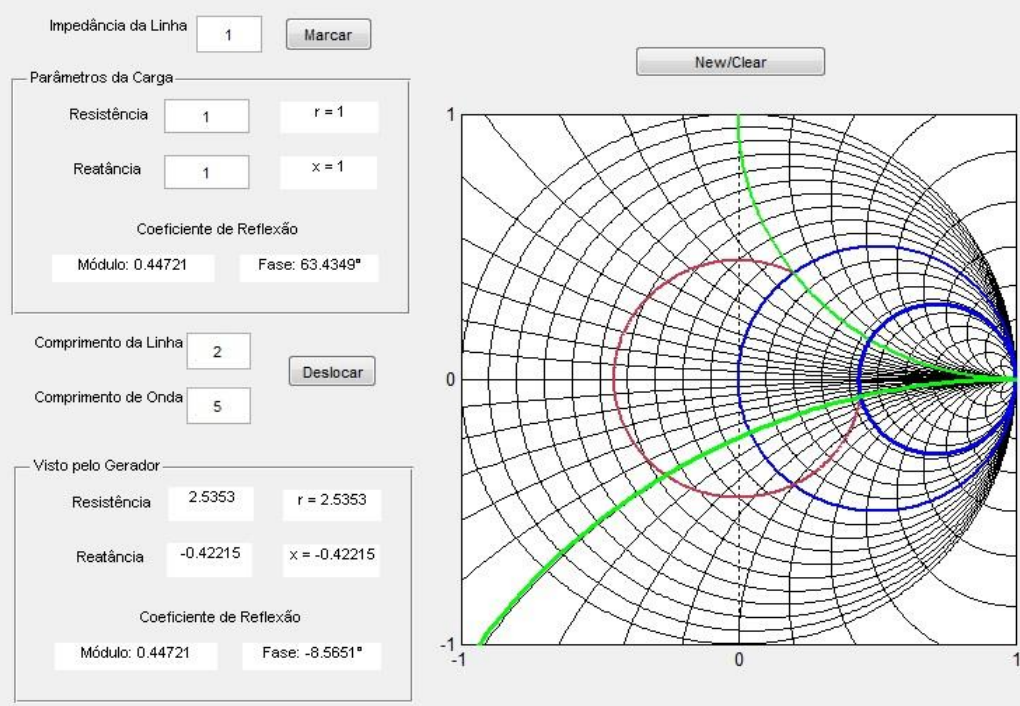

Figura 3: Deslocamento de impedância com a Carta de Smith

Palavras-chave: Criação de Interfaces, Eletromagnetismo, Plotagem Sequencial.

\section{Referências}

[1] J. D. Kraus, Eletromagnetics, McGraw-Hill, 4.ed, (1992).

[2] M. N. O. Sadiku, Elementos de Eletromagnetismo, Bookman, 5.ed, pp. 333-480, (2012).

[3] "MathWorks Products and Services", disponível em: www.mathworks.com 